\title{
ENDOMYOCARDIAL FIBROSIS IN TWO BROTHERS
}

\author{
BY \\ F. C. ADI \\ From University College Hospital, Ibadan, Nigeria
}

Endomyocardial fibrosis is a very rare form of heart disease in temperate climates but is fairly common in tropical and sub-tropical parts of Africa. Since Bedford and Konstam (1946) first described the disease in West African soldiers, many reports have appeared from various parts of Africa: from Uganda (Davies, 1948), the Sudan (O'Brien, 1954), Nigeria (Nwokolo, 1955; Abrahams, 1959, 1962), and from Kenya and Tanganyika (Turner and Manson-Bahr, 1960). In these areas, the disease afflicts the indigenous African populations almost exclusively, cases among the expatriate residents being very rare, although they have been described (Gray, 1951). Cases have also been reported from outside Africa, notably from America (Clark, Valentine, and Blount, 1956), Great Britain (Evans, 1957), and Holland (Van Buchem, Arends, and Schroder, 1959).

The ætiology of the disease is unknown. Malnutrition, infection, parasitic infestation, allergy, and lately rheumatic fever (Abrahams and Brigden, 1961) have been mentioned as being sometimes coexistent and therefore possible ætiological agents.

However, as yet there have been no reports of cases occurring in sibs, and for this reason, two brothers are reported in whom endomyocardial fibrosis was diagnosed clinically.

\section{CASE REPORTS}

Case 1. J.C., a 15-year-old boy, was first seen at the University College Hospital, Ibadan in September 1962. He gave a history of progressive abdominal swelling for two years. At the start of his illness, he had noticed some puffiness of his face but this had disappeared after about three months. His ankles had been slightly swollen occasionally. He denied any history of preceding sore throat, fever, or urinary abnormality.

In November 1961, 12 months after his illness began, he had repeated paracenteses abdominis at another hospital when about a gallon of fluid was removed each time. However, the abdominal 'swelling had quickly recurred after a few days. He stated that he felt generally well except for excessive tiredness on walking a short distance. He denied any breathlessness on walking or lying down.

Because of the abdominal swelling, he had travelled over three hundred miles to Ibadan to seek medical aid. His elder brother aged 17 years, had come with him because his abdomen too was getting swollen and he thought that he had the same disease.

There was nothing relevant in the past history. The family is shown in Fig. 1.

On examination, he looked well, although he was thin. The physical appearance was dominated by his grossly distending abdomen (Fig. 2B). He was quite comfortable lying flat in bed. He was well developed for his age. There was no pallor, digital clubbing, or cyanosis. The skin showed no evidence of malnutrition or filariasis. The jugular venous pressure was raised $20 \mathrm{~cm}$. above the sternal angle at $90^{\circ}$. It showed a vigorous systolic wave with deep ' $y$ ' descent. There was no ankle or sacral œdema. The arterial pulse was regular at $100 \mathrm{a}$ minute and of good volume. The blood pressure was $110 / 75 \mathrm{~mm}$. $\mathrm{Hg}$. There was an increase in cardiac dullness to the right of the sternum, and the apex beat was felt in the sixth left intercostal space outside the mid-clavicular line. There was a palpable left parasternal heave. The first and second heart sounds were of normal intensity and an atrial sound was present just to the left of the lower end of the sternum. A pan-systolic murmur was heard just to the left of the lower end of the sternum which was moderately loud and more marked on deep inspiration. 


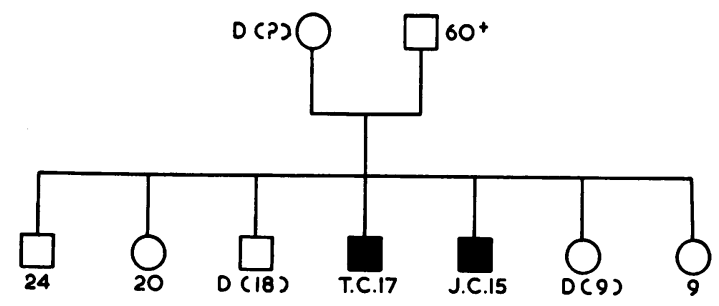

Fig. 1.-Family tree of the two brothers. $\square-$ males. $\quad \mathrm{D}=$ dead siblings; cause unknown. $\mathrm{O}$-females. $\mathbf{\square}=$ propositii. Numbers indicate present age of healthy living siblings. Numbers inside brackets indicate approximate age at time of death.

The liver was enlarged $10 \mathrm{~cm}$. below the right costal margin. It was firm, smooth, non-tender, and showed expansile systolic pulsation. The spleen was enlarged $4 \mathrm{~cm}$. below the left costal margin. There was a moderate ascites (an initially tense ascites had been partially tapped). There was no abnormality in the other systems.

Radiological examination revealed a greatly enlarged heart. A pericardial effusion was suspected (Fig. 4A). No calcification was seen. The cardiogram revealed sinus rhythm, and there was generalized low voltage QRS complexes. T waves were flat in most leads.

At cardiac catheterization (Fig. 3A) a pericardial effusion was shown to be present using Wood's (1951) technique of assessing thickness of the right atrial shadow. The right atrium was greatly enlarged making it very difficult for the catheter to enter the cavity of the right ventricle. A high mean right atrial pressure $(18 \mathrm{~mm} . \mathrm{Hg})$ and evidence of severe tricuspid regurgitation were found during an episode of supraventricular tachycardia. The cavity of the right ventricle was entered with great difficulty but the catheter could not be advanced very far. Pressure tracing from this cavity showed a dip-and-plateau curve during sinus rhythm. The pressure was $18 / 14 \mathrm{~mm}$. $\mathrm{Hg}$.

The urine showed no abnormality. The hæmoglobin was $11 \mathrm{~g} .(75 \%)$ and the leucocyte count was $7600 /$ c.mm., with 50 per cent eosinophils. Apart from some ova of hookworm in the stools, there was no other detectable cause for the eosinophilia. The serum proteins showed a total protein of $8.9 \mathrm{~g} . / 100 \mathrm{ml}$.; albumin $2.9 \mathrm{~g}$. and globulins $6 \mathrm{~g} . / 100 \mathrm{ml}$.

Liver function tests revealed thymol turbidity 5.8 units; thymol flocculation positive; bilirubin and alkaline phosphatase normal. The ascitic fluid contained a few mononuclear cells and showed a protein content of $4.4 \mathrm{~g} . / 100 \mathrm{ml}$. Liver biopsy showed dilated sinusoids and some fibrosis distorting the portal tracts and hepatic lobules but not true cirrhosis.

Case 2. T.C., a 17 year-old apprentice carpenter, and elder brother of J.C. above, stated that his abdomen had been steadily swelling for four months. He said that at the beginning of his illness he felt feverish, had headaches, and his eyelids were puffy in the mornings, but all these symptoms had stopped after one week. He denied any history of preceding sore throat, urinary abnormality, or swelling of his ankles. He had noticed some breathlessness whenever he rode his bicycle up a steep hill but he had never had any nocturnal dyspnœa and was able to lie flat in bed without any difficulty.

On examination he looked well and comfortable lying flat in bed. His abdomen was distended (Fig. 2). There was no pallor, digital clubbing, or cyanosis.' No ankle or sacral œdema was detected. The jugular venous pressure was raised to $12 \mathrm{~cm}$. above the sternal angle at $90^{\circ}$ and showed a vigorous systolic pulsation. The pulse was regular at 96 a minute and of good volume. The blood pressure was $110 / 60 \mathrm{~mm}$. $\mathrm{Hg}$. The heart was enlarged, the apex beat being felt in the 6th left intercostal space outside the mid-clavicular line. There was a palpable left parasternal heave. A third heart sound and a pan-systolic murmur of moderate intensity could be heard down the left sternal edge, and towards the apex of the heart. The liver was enlarged $7 \mathrm{~cm}$. below the right costal margin: it was firm, smooth, non-tender, and showed a marked expansile systolic pulsation. The spleen tip could be felt. Moderate ascites was present.

Radiological examination (Fig. 4B) revealed an enlarged heart. No calcification was seen. The cardiogram showed sinus rhythm, the QRS complexes were of low voltage, and the T waves were flat in most leads.

At cardiac catheterization (Fig. 3B) no pericardial effusion was demonstrated. The cavity of the right atrium was large. Tracing taken from this cavity showed a small ' $a$ ' wave and also a prominent positive $2 w^{*}$ 


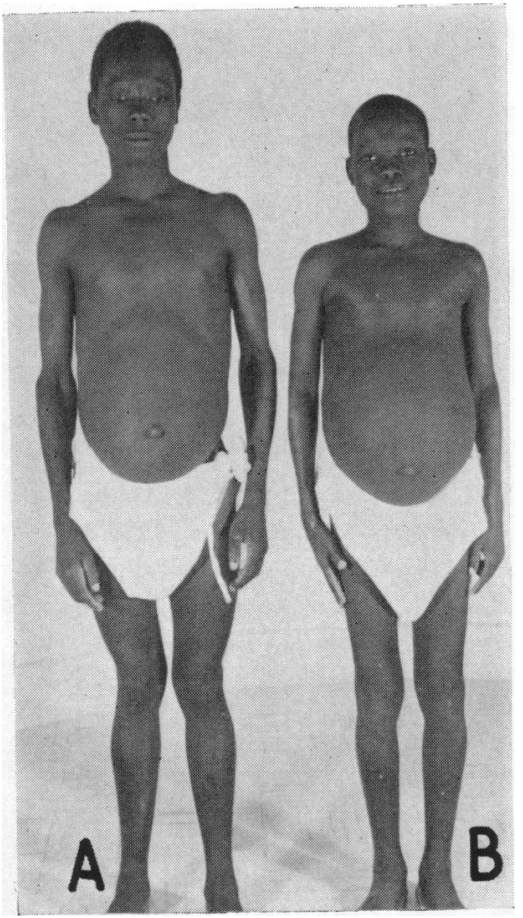

FIG. 2.-Photograph of the two brothers. (A) T.C. (Case 2) (17 years).

(B) J.C. (Case 1) (15 years).

Note ascites without odema of the legs.
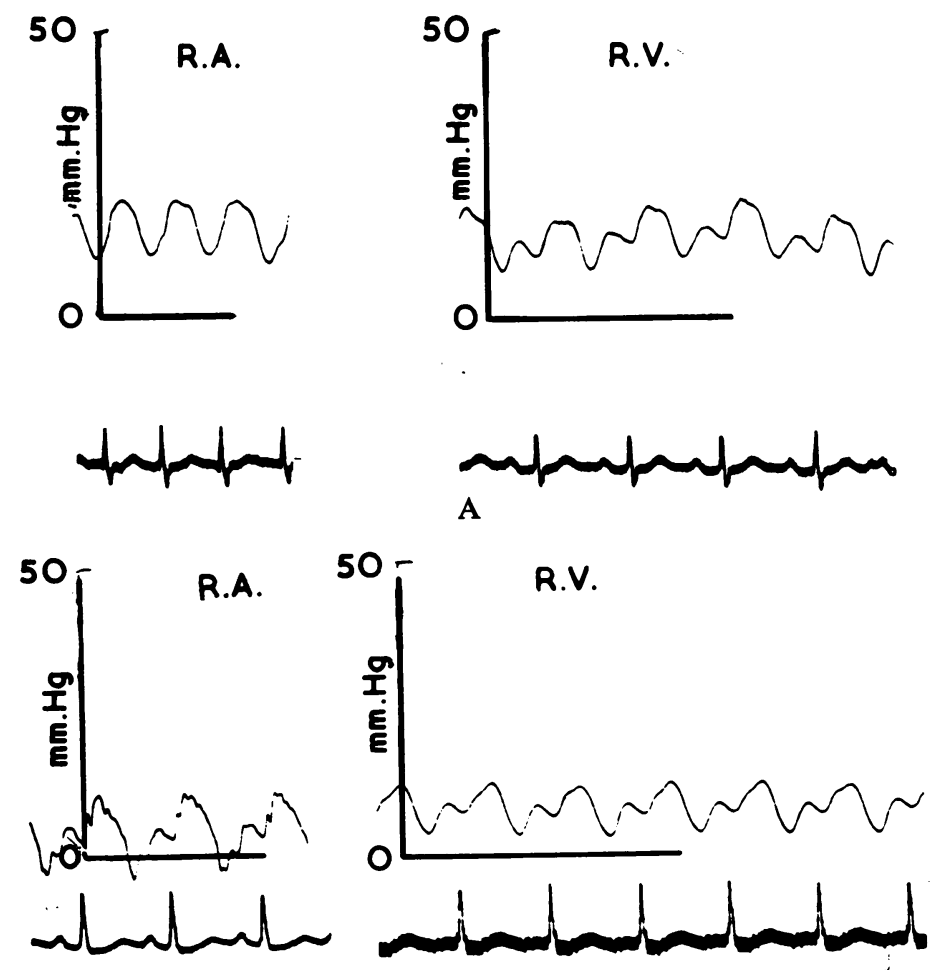

B

FIG. 3-(A) Intracardiac pressure tracing taken during paroxysm of supraventricular tachycardia, showing marked positive systolic wave in the right atrium indicating gross tricuspid regurgitation. Note also the dip-and-plateau pattern of the tracing from the right ventricle. (B) Pressure tracings taken from the brother, T.C. Tracing from the right atrium shows a small ' $a$ ' wave and also a positive systolic wave. Tracing from the right ventricle shows a dip-and-plateau curve very similar to that of his brother, J.C.

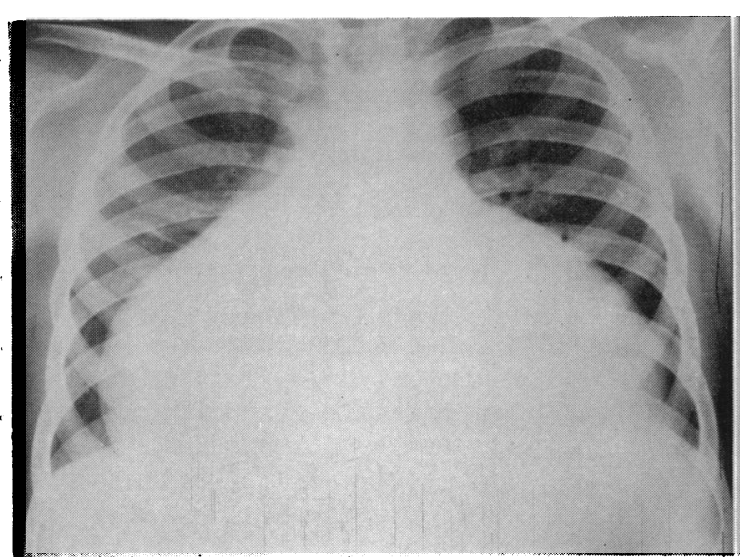

A

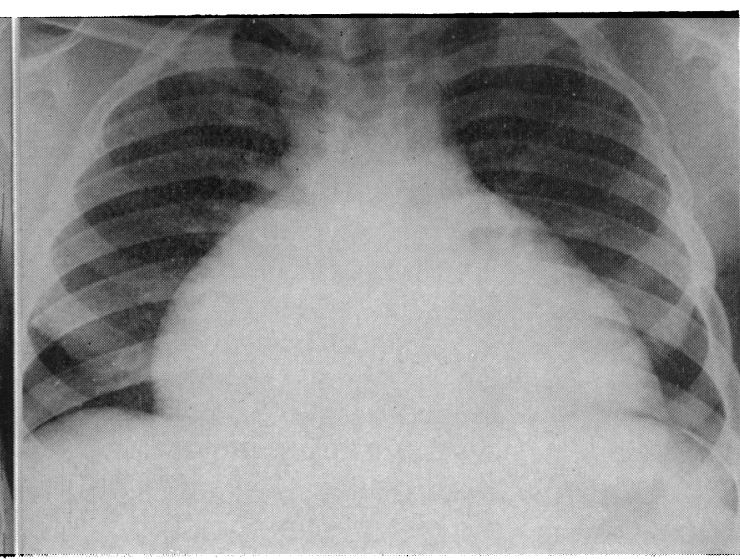

B

FIG. 4.-(A) Postero-anterior chest radiograph of J.C. (Case 1) showing gross cardiomegaly. A small pericardial effusion was shown to be present on cardiac catheterization. (B) Chest radiograph of T.C. (Case 2) also showing cardiomegaly. 
systolic wave indicating tricuspid regurgitation. A dip-and-plateau tracing similar to that of his brother, J.C., and measuring $12 / 10 \mathrm{~mm}$. $\mathrm{Hg}$ was obtained from the cavity of the right ventricle.

The urine was normal. The hæmoglobin was $12 \cdot 3 \mathrm{~g}$. $(84 \%)$; leucocyte count, 4800 with a normal differential count. The serum proteins showed a total of $7.5 \mathrm{~g} . / 100 \mathrm{ml}$.; albumin $3.0 \mathrm{~g} . / 100 \mathrm{ml}$., and globulins $4 \cdot 5 / 100 \mathrm{ml}$. Liver function tests were normal. The ascitic fluid contained only a few endothelial cells and showed a protein content of $5.6 \mathrm{~g} . / 100 \mathrm{ml}$. Liver biopsy showed features essentially similar to those of his brother, J.C.

\section{Discussion}

These case reports show that the two brothers are probably suffering from the same disease. An excellent description of the clinical and other features of endomyocardial fibrosis when it affects the right ventricle has been given by Abrahams (1962). He described cases very similar to our two, with cardiac enlargement, particularly of the right atrium, high jugular venous pressures, and gross tricuspid regurgitation. Other features of the disease include grossly enlarged livers (showing fibrosis) and a clinical appearance dominated by gross ascites and absent ankle œedema. The two brothers had all these features. The disease resembles constrictive pericarditis in many ways. The appearance of the patient and often the electrocardiogram may be deceptively similar in both diseases. The dip-and-plateau pattern of the ventricular tracings may be seen in both endomyocardial fibrosis and constrictive pericarditis, as in both instances there is a limitation of ventricular filling. However, large hearts and gross tricuspid regurgitation are not features of constrictive pericarditis whereas they are the rule in established right-ventricular endomyocardial fibrosis. Some of the patients with clinical and other features similar to those of the two brothers just described have been followed to autopsy in this hospital and all have shown similar changes. There is usually gross endomyocardial fibrosis affecting the right ventricle. The fibrosis greatly reduces the size of this chamber sometimes almost obliterating it. Involvement of the papillary muscles causes the tricuspid valve leaflets to be pulled down and this produces severe tricuspid valve incompetence. The right atrium dilates sometimes reaching aneurysmal proportions.

The disease can of course affect one or other ventricle or both together. The cases described above show the clinical picture seen when the right ventricle is predominantly affected.

This occurrence of the disease in sibs raises the question of whether a common environmental agent is responsible for the disease in these two brothers or whether some hereditary influence is at work. Before any conclusions can be drawn, it is obvious that many more such cases will have to be searched out and studied.

\section{SUMMARY}

Case reports of two brothers, born of the same father and mother, are presented showing the clinical, radiological, and hæmodynamic features suggestive of right-sided endomyocardial fibrosis.

This is the first report of the occurrence of this disease in sibs.

I wish to express my sincere gratitude to Dr. T. Ogunlesi for permission to study these patients, to Dr. E. Parry for his constant advice and encouragement, and to Mr. F. Speed for taking the photographs.

\section{References}

Abrahams, D. G. (1959). An unusual form of heart disease in West Africa: its relation to endomyocardial fibrosis. Lancet, $2,111$.

- (1962). Endomyocardial fibrosis of the right ventricle. Quart.J. Med. (n.s.), 31, 1.

- and Brigden, W. (1961). Syndrome of mitral incompetence, myocarditis, and pulmonary hypertension in Nigeria. Brit. med. J., 2, 134.

Bedford, D. E., and Konstam, G. L. S. (1946). Heart failure of unknown ætiology in Africans. Brit. Heart J., 8, 236. Clark, G. M., Valentine, E., and Blount, S. G., Jr. (1956). Endocardial fibrosis simulating constrictive pericarditis.
New Engl. J. Med., 254, 349. 
Davies, J. N. P. (1948). Endocardial fibrosis in Africans. East Afr. med. J., 25, 10.

Evans, B. (1957). Obscure cardiopathy. Brit. Heart J., 19, 164.

Gray, I. R. (1951). Endocardial fibrosis. Brit. Heart J., 13, 387.

Nwokolo, C. (1955). Endomyocardial fibrosis and other obscure cardiopathies in Eastern Nigeria. W. Afr. med. J. (n.s.), 4, 103.

O'Brien, W. (1954). Endocardial fibrosis in the Sudan. Brit. med. J., 2, 899.

Turner, P. P., and Manson-Bahr, P. E. C. (1960). Endomyocardial fibrosis in Kenya and Tanganyika Africans. Brit. Heart J., 22, 305.

Van Buchem, F. S. P., Arends, A., and Schroder, E. A. (1959). Endocardial fibro-elastosis in adolescents and adults. Brit. Heart J., 21, 229.

Wood, P. (1951). Diagnosis of pericardial effusion by means of cardiac catheterization. Brit. Heart J., $13,574$. 